\title{
Sébastien Prat, Constance et inconstance chez Montaigne
}

\section{Pierangela Adinolfi}

\section{Q OpenEdition}

1 Journals

\section{Edizione digitale}

URL: http://journals.openedition.org/studifrancesi/3703

DOI: $10.4000 /$ studifrancesi.3703

ISSN: 2421-5856

\section{Editore}

Rosenberg \& Sellier

\section{Edizione cartacea}

Data di pubblicazione: 1 décembre 2012

Paginazione: 557

ISSN: 0039-2944

\section{Notizia bibliografica digitale}

Pierangela Adinolfi, «Sébastien Prat, Constance et inconstance chez Montaigne», Studi Francesi [Online] 168 (LVI | III) | 2012, online dal 30 novembre 2015, consultato il 08 mars 2021. URL: http:// journals.openedition.org/studifrancesi/3703 ; DOI: https://doi.org/10.4000/studifrancesi.3703

Questo documento è stato generato automaticamente il 8 mars 2021.

\section{(c) (i) $\odot$}

Studi Francesi è distribuita con Licenza Creative Commons Attribuzione - Non commerciale - Non opere derivate 4.0 Internazionale. 


\title{
Sébastien Prat, Constance et inconstance chez Montaigne
}

\author{
Pierangela Adinolfi
}

\section{NOTIZIA}

SÉBASTIEN PRAT, Constance et inconstance chez Montaigne, Paris, Classiques Garnier, 2011, pp. 502.

1 Il presente e poderoso volume ha origine dalla tesi di dottorato in filosofia presentata nel 2009 all'Université de Montréal e all'Université Paris-Sorbonne da Sébastien Prat. Il libro assume come punto di partenza la doppia constatazione riguardante da un lato l'incremento del discorso sulla costanza nell'ambito politico-morale della fine del XVI secolo e dell'inizio del XVII, dall'altro lato l'insistenza degli Essais di Montaigne sul fenomeno contrario e cioè l'incostanza. All'interno del neostoicismo che domina il dibattito filosofico dell'epoca (Juste Lipse, Guillaume du Vair, Charron), la nozione di costanza acquisisce una nuova estensione concettuale che la rende sinonimo di virtù. Gli Essais di Montaigne presentano, invece, una riflessione critica a proposito della «vertu de constance», insistendo pesantemente sull'incostanza umana e universale. Tema già notato da illustri critici come Pierre Villey e Hugo Friedrich, ma non studiato in maniera approfondita come sottolinea l'A., l'incostanza diventa il fulcro della prospettiva che Sébastien Prat adotta nell'analisi dei Saggi di Montaigne. Il volume si apre con un'ampia «Introduction» (pp. 9-35) alla quale seguono tre sezioni. La prima: «Sources et réception de l'inconstance dans les Essais» (pp. 39-199). In questa parte l'A., dopo aver riscontrato il posto che l'incostanza occupa negli Essais, analizza il rapporto di Montaigne con lo scetticismo, lo stoicismo e l'epicureismo, alla luce del tema dominante. L'incostanza è, quindi, per Montaigne un tratto caratteristico dell'umanità. L'A. esamina il concetto da un punto di vista psicologico, morale e nel rapporto dell'uomo col soprannaturale. La seconda: «Les effets de l'inconstance sur la méthode des Essais et dans la sphère publique» (pp. 203-360). Dopo aver trattato i problemi posti dall'incostanza, ora l'A. considera le conseguenze derivanti dalle precedenti 
acquisizioni. Invece di fondare la propria riflessione lontano dall'«inconstance» e di esortare vanamente il lettore alla "constance», Montaigne, in opposizione alle tradizioni culturali alle quali attinge, sviluppa le conseguenze filosofiche, cognitive, etiche e letterarie inerenti all'esperienza dell'incostanza umana. Tale prospettiva presenta risvolti metodologici, politici e pubblici negli Essais. La terza: «Les conséquences éthiques de l'inconstance» (pp.363-465). Se la seconda sezione riguardava le ripercussioni cognitive e politiche dell'incostanza negli Essais ed in particolare nell'ambito della sfera pubblica, la terza è dedicata all'esame degli effetti dell'«inconstance» nella dimensione privata di Montaigne, a partire dalla condotta etica della propria esistenza. Il terzo libro degli Essais dà vita a molteplici regole etiche stupefacenti ed eterodosse: «non repentir, diversion, vanité, expérience». Tutte prendono come punto di riferimento il «possible» e contribuiscono a ridefinire la "grandeur d'âme», presentando un nuovo ordine d'azione. Negli Essais, l'etica di Montaigne è in accordo col movimento imperfetto ed incostante dell'esistenza. L'«étique de l'inconstance» o "étique de l'indirection» è costruita in opposizione alle dottrine morali con le quali, tuttavia, il dialogo è continuo. Segue la «Conclusion» (pp. 467-481). La «Bibliografia» e l'«Indice dei nomi» chiudono il volume. 